\title{
AS ESCOLAS EMPREENDEDORAS: FOCO NA EFICIÊNCIA E NA QUALIDADE DOS PROCESSOS
}

\author{
Carlos Navarro Fontanillas (UFRJ) \\ navarro@pep.ufrj.br \\ Carlos José Guimarães Cova (UFF) \\ cjcova@terra.com.br
}

\section{RESUMO}

No futuro, aumentará a tendência de empresas orientadas a projetos com uma estrutura bem diferente das tradicionais. A função de produção será uma das mais importantes dimensões da organização, porque a sua concepção afetará diretamente o nível pelo qual ela satisfaz os seus consumidores. Os recursos de entrada (input) poderão ser classificados como sendo de transformação (instalação e funcionários) que deverão atuar em direção aos recursos transformados (materiais, informações e consumidores). A maioria dos colaboradores será constituída por profissionais da área de conhecimento, que circulam por diferentes projetos para atender às demandas dessa estrutura organizacional, buscando reunir todas as forças necessárias para atingir o objetivo estratégico. Os profissionais do conhecimento não estão mais subordinados a chefes inflexíveis, mas sim a fornecedores de serviços em um mercado livre. No caso da empresa intra-empreendedora, muitos dos fornecedores serão equipes internas que ainda estarão na condição de empregados da empresa, tanto no sentido legal quanto pelo fato de pertencerem a ela.

Palavras Chave: Intraempreendedorismo. Cultura cooperative. Cliente interno. Escolas de pensamento.

\section{ABSTRACT}

In the future, it will increase the trend of guided companies the projects with a well different structure of the traditional ones. The production function will be one of the most important dimensions of the organization, because its conception will directly affect the level for which it satisfies its consumers. The entrance resources (input) could be classified as being of transformation (installation and employees) that they will have to act in direction to the transformed resources (material, information e consumers). The majority of the collaborators will be constituted by professionals of the knowledge area, who circulate for different projects to take care of to the demands of this organizacional structure, searching to congregate all the forces necessary to reach the objective strategical. The professionals of the knowledge are not more subordinated the inflexible heads, but yes the suppliers of services in a free market. In the case of the company intra-entrepreneur, many of the suppliers they will be internal teams that still will be in the condition of used of the company, as much in the legal direction how much for the fact of to belong it.

Words Key: Intra-entrepreneur. Cooperative culture. Internal customer. Schools of thought. 


\section{INTRODUÇÃO}

Apesar do tempo em que o termo é usado e estudado, o termo empreendedorismo está longe de ser um consenso na doutrina acadêmica. De acordo com o julgamento de Lischeron (1991) ainda se sabe muito pouco sobre o assunto. A visão inicial nos remete à alguma competência distintiva por parte daqueles que começa um negócio. Tal concepção excluiria aqueles que herdam ou compram uma empresa, embora atualmente, com a atual onde de fusões e aquisições, a compra de uma empresa possa ser também entendida como sendo o resultado de uma visão empreendedora. Como exemplo dessa espécie de empreendedor, é possível citar Henry Ford II ou indivíduos que promoveram mudanças significativas como empregados em uma organização. Não obstante, há também aqueles que aplicam o termo referindo-se a quem desenvolve atividades ligadas a inovação, não considerando a grande parcela de pessoas que montam e gerenciam um negócio.

Segundo o autor citado, com base nestes argumentos é possível perceber como as definições encontradas são bem distintas. Dessa forma, mais do que definir o termo, ele propõe um estudo sob as diferentes perspectivas de pensamento que abordam o estudo. Nessa medida, Lischeron nos aponta seis escolas de pensamento do empreendedorismo.

São elas:

\section{ESCOLA CLÁSSICA}

A escola clássica reflete o pensamento; inicialmente desenvolvido por Schumpeter, citado por Kornijezuk (2004), apresentando a inovação como a característica central do comportamento empreendedor. A capacidade de inovar se contrapõe ao pensamento dos "donos" do negócio, e nos remete aqueles que desenvolvem novos produtos, mercados, ou processos com base na criatividade e inovação. Em resposta, algumas características pessoais, tais como o individualismo e a independência, associadas a pessoas criativas e inovadoras, são atribuídas aos agentes empreendedores, segundo esta escola.

\section{ESCOLA DA GESTÃO}

A escola da gestão afirma que o empreendedor é aquele que organiza ou gerencia um negócio, assumindo seus riscos em busca de lucros. Mais especificamente, este deve ser responsável por, planejar, organizar, alocar pessoas, orçar, coordenar e controlar. Nesse sentido, o viés dessa escola está orientado mais na capacidade administrativa do agente, do que propriamente num talento ou dom extraordinário.

Esta escola lida com aspectos mais técnicos de gerenciamento, definindo objetivos claros ao negócio e na formação dos colaboradores e suas habilidades gerenciais.

\section{ESCOLA DO “GRANDE HOMEM”}

Baseia-se nas biografias de grandes personagens com sucesso empresarial como Bill Gates, Roberto Marinho, dentre outros. A escola sugere que o empreendedorismo é uma habilidade restrita a alguns indivíduos que se destacam por suas aptidões naturais. Permitem que estas pessoas reconheçam oportunidades e tomem decisões apropriadas, diferente dos demais mortais, que não tiveram o privilegio de nascer com esta habilidade intuitiva especial.

Assim, para a escola, o empreendedor já nasce pronto, não pode ser formado. 


\section{ESCOLA DA LIDERANÇA}

Defende que os empreendedores são essencialmente líderes e teriam a capacidade de motivar e criar empatia entre seus comandados, para que todos se empenhem em uma realização comum. Mais do que direcionar pessoas, o empreendedor acompanha e desenvolve-as, alem de ser um elo social entre os colaboradores, permitindo uma constante troca de informações com o grupo e o ambiente externo.

\section{ESCOLA DO EMPREENDEDORISMO}

Finalmente, a escola do empreendedorismo é aquela que sugere atividades ligadas a inovação podem contribuir para o ambiente organizacional. Nesse sentido, cada colaborador pode funcionar como um agente de transformação endógeno, numa perspectiva de intraempreendedorismo. 0 intraempreendedor seria aquele agente que, dentro da organização, conta com certa liberdade para desenvolver e implementar inovações sem necessariamente terem estas idéias como suas, já que elas acabam pertencendo a organização.

Criar um ambiente de criatividade não consiste em incentivar iniciativas individuais. Ao contrario, ele se desenvolve num ambiente de união entre os membros da organização, onde se detectam as oportunidades de melhoria a partir do trabalho em equipe e das diferentes visões postas lado a lado. A essência dessa visão é a manutenção de um permanente ambiente de colaboração entre os atores para que estes possam compartilhar suas vivências numa rede sinérgica de potencialização de conhecimento.

A busca pela eficácia e qualidade dos processos, bem como pela vantagem competitiva, concorre para que venha aumentando significativamente o número de empresas que adotam programas intraempreendedores de qualidade e sistemas de gestão. Porém, nem sempre esses programas e sistemas são eficazes, já que exigem um forte investimento, além de gerar recorrentemente, uma resistência cultural dos membros das organizações. Em geral, o principal óbice para o sucesso de uma iniciativa dessa natureza tem sido o componente cultural das organizações, que tende a manter os agentes na chamada "zona de conforto", obstruindo qualquer tentativa de mudanças.

Sistemas de gestão da qualidade, como por exemplo as normas da série ISO 9000, exigem da empresa um esforço para mudar toda maneira de trabalho na organização. Não obstante, se eles não forem bem implementados e encaixados no perfil da empresa, os efeitos gerados podem ser contraproducentes, levando à burocratização dos processos, que passam a ser um fim em si mesmos. Tal situação configura um estado da natureza que acaba por deixar de ter como foco a melhoria da organização.

A partir das linhas de contorno deste contexto, pretendemos apresentar alguns exemplos da adoção de metodologias de melhoria de processo em grandes empresas, por parte de administradores de sucesso, de tal forma a reafirmar a convicção de que a previsão e implementação de uma arquitetura organizacional e de um modelo de gestão, que tenham como principal objetivo a melhoria de todo o processo interno e a ampliação da capacidade de aprendizado e de inovação de seus colaboradores, com um escopo de atuação voltado para os seguintes aspectos: fluxo de informações, foco em resultados e clientes, motivação dos recursos humanos e intra-empreendedorismo.

\section{ARQUITETURA E GESTÃO DA ORGANIZAÇÃO BASEADA NO INTRA- EMPREENDEDORISMO}


As organizações são sistemas abertos, isto é, são entidades complexas compostas dos seguintes elementos caracterizadores: um conjunto de partes inter-relacionadas, também designadas por subsistemas; uma região de fronteira com o ambiente; e por relações com esse ambiente.

Nesse sentido, recebem do ambiente; estímulos, que são entradas (input). Submetem estas entradas a um processamento (transformação). E geram para o ambiente algumas respostas, que são as saídas (output).

Além disso, os sistemas estão em permanente retro-alimentação, ou seja, recebem um feedback (interação e resposta do mercado - clientes, concorrentes, fornecedores, etc.). Esse grande sistema, que representa a organização empresarial, também é composto de um conjunto de subsistemas que seguem a mesma estrutura já descrita.

Neste artigo, iremos dividir a organização em subsistemas, que serão designados por UIN's (Unidade Interna de Negócio). Em seguida será feita uma descrição de métodos tradicionais para o desenvolvimento e administração de portfólios de negócios, buscando sinergias e aproveitando capacidades e relacionamentos dos colaboradores na organização.

Numa empresa, seja ela grande ou pequena, quase todo o trabalho está voltado para o atendimento de demandas e necessidades de agentes que estão dentro dela, ou seja, os clientes internos. Desta forma um dos problemas que se apresenta diante dos gestores da organização é: como tornar os provadores de serviços internos mais inovadores, eficazes, orientados ao cliente?

A doutrina afirma que devem ser disponibilizadas para os clientes internos múltiplas opções, dentre os vários fornecedores internos intra-empreendedores, de tal forma a permitir que tais intra-empresas vendam seus serviços na empresa inteira.

Nossa convicção é a de que a maioria dos colaboradores trabalhará em intra-empresas prestadoras de serviços internos. A percepção da existência de clientes internos por parte desses colaboradores, fará com que eles fiquem alinhados com o cumprimento da missão da empresa. Nesse sentido, tanto o consumidor interno quanto o fornecedor interno podem ser usados para descrever aqueles que recebem inputs de qualquer operação.

Sendo assim, os consumidores e os fornecedores internos formam uma microoperação. Desta maneira podemos modelar qualquer função produção como uma rede de micro-operações que estão engajadas em transformar materiais, informações ou consumidores (ou seja, funcionários), sendo ao mesmo tempo, uma fornecedora interna de bens e serviços de outras micro-operações.

Assim, devemos registrar que existem diferenças entre os consumidores internos e externos. 0 primeiro nos fornece um modelo que permite a análise das atividades internas de uma operação. Se a macro-operação não está funcionando como deve, podemos rastrear o problema ao longo da rede interna de consumidores e fornecedores. 0 segundo consumidor configurar-se-ia num conceito útil para todas as partes do negócio, na medida em que, quando seus clientes internos fossem tratados com o mesmo grau de cuidado que é dedicado aos consumidores externos, poderia ocorrer a melhoria da eficácia das operações como um todo.

Quando fossem responsáveis por seus próprios centros de lucro internos, os intraempreendedores de serviços seriam re-alocados para as atividades onde são capazes de incorporar um maior valor. Através do feedback de clientes, eles aprenderiam a atender as 
reais necessidades dos clientes de forma mais rápida, melhor e mais econômica. Como resultado, teremos uma empresa totalmente intra-empreendedora com relevantes avanços em termos de inovação e aumento de produtividade.

Figura 1 - Modelo de entradas e saídas

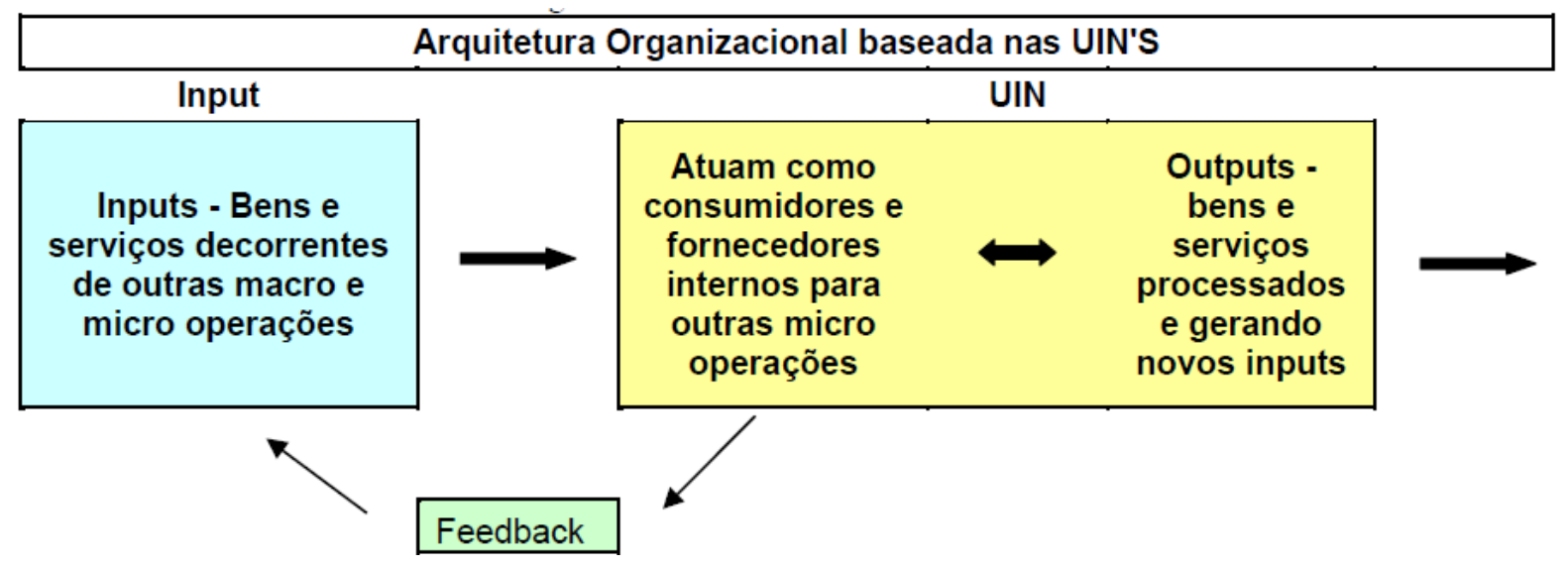

Fonte: SLACK, N. Administração da Produção, São Paulo, Atlas, 1999

Na empresa do futuro, o conceito de intra-empresa livre será muito difundido. De acordo com Pinchot (1999), e conforme a esquematização apresentada na figura anterior, todas as atividades de empregados podem ser consideradas serviços prestados a outras pessoas dentro da empresa. Nessa concepção filosófica, a maioria desses serviços será melhor realizado na medida em que sejam prestados por intra-empresas, do que por empregados subordinados a controles da cadeia de comando tradicional. A maior parte dos empregados será, então, constituída por intra empreendedores, que operam intra-empresas de serviço interno. Os prestadores de serviço, de acordo com esta nova visão, não estariam fora de controle e seriam orientados no sentido de estarem em permanente alinhamento com a missão institucional.

Entrementes, esta nova filosofia de trabalho promoveria uma sinergia positiva para atender as necessidades articuladas e concebidas pela estrutura organizacional, pois ela procuraria cumprir a missão da organização e permitiria satisfazer o cliente com um conteúdo utilitário satisfatório, tanto em termos de margem de lucro, quanto com relação aos benefícios incorporados ao produto.

Nesse novo ambiente, os empregados teriam uma maior liberdade e mais responsabilidade. Por outro lado, é inevitável que eles se tornem responsáveis pela renovação de sua própria habilidade de adicionar conhecimento e valor a projetos. Caso contrário, sua própria capacidade de encontrar novos postos de trabalho poderia ficar prejudicada.

Apesar do fato de serem empregados, eles estarão negociando de forma endógena para entregar serviços a inúmeros clientes em potencial e competindo com muitos outros profissionais com o mesmo nível de conhecimento. Sua flexibilidade incentivará a transferência de tecnologia e aprendizagem, rompendo muitas barreiras na empresa.

Atuando nessa perspectiva, as equipes desenvolveriam continuamente novos recursos e habilidades, que as manteriam valorizadas e com perspectivas sólidas, de tal forma que pudessem aplicar seus resultados em novas ferramentas para oferecer treinamento e aumentar a produtividade. 
Como resultados positivos dessa nova concepção organizacional, deverão surgir muitos idealizadores valiosos distribuídos por todo negócio, que estarão explorando e desenvolvendo as principais competências que trarão futuras vantagens competitivas para a empresa como um todo.

0 resultado de uma estrutura de intra-empresa será a criação de um novo conceito com grande capacidade de aprendizagem. As empresas aprendem através de novos relacionamentos estabelecidos entre indivíduos e equipes. As empresas do futuro são sistemas com organização própria, em que cada pessoa e cada equipe deverão buscar continuamente novas formas para ampliar o seu valor intrínseco e aumentar a sua contribuição para o core business da organização. 0 mercado interno fornece o feedback necessário para direcionar esta atividade com orientação própria em função dos aspectos positivos da empresa e dos clientes externos.

As empresas geralmente desenvolvem exércitos de especialistas, que, no entanto, manifestam pouca experiência relativa às habilidades gerenciais, que seriam determinantes para o êxito de suas ações. Tal circunstância evidencia adicionalmente uma falta de conhecimentos gerais no âmbito do comportamento organizacional.

Nas UINs todas as equipes intra-empreendedoras aprenderão a julgar negócios e pessoas que as integram, na medida em que operam as suas próprias intra-empresas. Desde o início de suas carreiras, os membros das equipes ajudarão a gerenciar pequenos centros de lucro e aprenderão com a experiência dos sucessos e fracassos das equipes.

Quando ocorrer o momento de localizar talentos gerenciais gerais para o provimento de cargos da estrutura organizacional, muitos colaboradores experientes e testados estarão disponíveis. Será possível conhecê-los através da análise do histórico de suas realizações dentro da corporação.

Uma das equipes líderes na construção deste tipo de arranjo organizacional é a IBM, que adota o conceito de ter o indivíduo certo no lugar certo, de tal forma a otimizar o esforço de trabalho e ampliar a eficiência da companhia. Segundo Oliveira, presidente da IBM Brasil, uma boa parte do seu tempo de trabalho é dedicado pessoalmente ao atendimento do lado humano da organização, fomentando o desenvolvimento das pessoas, integrando-as entre si, e escolhendo novos talentos por sua capacidade de trabalhar em equipe.

Não obstante, mesmo com relação ao perfil intra-empreendedor, não se deve perder de vista as lições exaradas de Levitt (1975) no tocante ao foco no cliente. $O$ fundamental continua a ser o cliente, e não os produtos ou os processos que procuram atendê-lo. 0 perfil deste indivíduo deve ser voltado para inovar. Motivação é a palavra chave com premiação ao alcance de metas, o que faz pessoas pensarem e atuarem de modo inovador. A implantação deste projeto teve um alinhamento mundial, com uma espinha dorsal integradora com delegação de poder para as pontas da linha, a fim de garantir a capacidade de implementação local, pois países como Brasil, Japão e Canadá têm diferenças fundamentais.

Um outro exemplo da aplicação desse conceito é a Microsoft, uma empresa que acredita que faz produtos que mudam o mundo. Os seus colaboradores se orgulham disso e estão totalmente imbuídos na missão da organização. Mais do que qualquer outro motivador o esforço coletivo e a iniciativa individual fazem à diferença em diversas situações.

Uma vez que os comportamentos individuais determinam o sucesso de uma empresa ao longo do tempo, o primeiro passo para resolver as disfunções de uma organização seria perguntar, 
quais são os fatores que influenciam o comportamento de cada indivíduo e afetam seu desempenho? Existem algumas bases a serem consideradas para obtenção dessa resposta, tais como: estrutura, direitos de decisão, itens motivacionais e fluxo de informações.

A estrutura organizacional deve admitir um organograma e seguir o planejamento estratégico da unidade de negócios. Um problema estrutural comum que impede a execução da estratégia é a existência de muitos degraus gerenciais, com excesso de profissionais em cada degrau com poucos subordinados diretos. A mudança estrutural tem como finalidade reduzir níveis e aumentar produtividade, acrescentando subordinados diretos a cada executivo e melhorando o comportamento dos colaboradores, bem como o fluxo de informação. Para isso a empresa deve determinar padrões claros de forma que a alta direção não precise rever e aprovar todas as transações, bastando apenas utilizar relatórios mensais, de tal forma que possa rastrear as exceções e aferir a conformidade às regras. Por fim, devem ser realizados mais treinamentos e ampliada à comunicação, de tal maneira que a organização retome sua vantagem competitiva.

Os direitos de decisão especificam quem tem autonomia para tomar quais decisões.

Esse esclarecimento dá nova vida ao organograma e deixa bem claro onde está a responsabilidade. Direitos de decisão claros dão margem a amplitudes maiores e menos níveis, o que se traduz em custos mais baixos e execução mais rápida.

Uma solução adequada para o gerenciamento do processo decisório no estabelecimento de um processo para que os diretores corporativos delegassem decisões para os gerentes gerais da unidade de negócio, criando um comitê executivo para revisar as decisões da unidade e vários gerentes gerais passaram a integrar o marketing, o desenvolvimento de produtos e a produção, o que permitiu uma delegação efetiva.

Neilson(2002) sugere que não seria preciso uma aquisição para alterar a estrutura de direitos de decisão de uma empresa. As pessoas naturalmente tendem ao que é familiar quando enfrentam mudanças. Os executivos promovidos para novos cargos frequentemente se apegam a suas responsabilidades anteriores, encarregando-se de tarefas desnecessárias e retirando o poder de seus subordinados, onde a alçada para a tomada de decisão de menor amplitude, se mostra como solução concreta.

Nos itens motivacionais, os empregados geralmente não agem de forma contraproducente de propósito. Ao contrário, respondem bem racionalmente com base no que vêem, no que entendem e na maneira pela qual são recompensados. Em uma empresa de bens de consumo, os funcionários eram avaliados numa escala de 1 a 10. Oitenta por cento deles receberam classificação de 9 ou 10, e todos se sentiram bem. Entretanto, os funcionários de melhor desempenho achavam que não precisavam melhorar, outros achavam que seu desempenho era aceitável, quando não era. Cada colaborador deficiente que permaneceu prejudicou a capacidade de execução da empresa, que, assim, perdeu a oportunidade de lhe enviar um feedback importante sobre o que era relevante para implementar a estratégia.

As organizações que estiverem prontas para implantar demonstrações múltiplas de lucros e perdas com sistemas motivacionais baseados no mercado, constatarão que estas ferramentas podem ajudá-las a funcionar eficazmente com menos supervisão de comando e controle. Contudo nem todas estão prontas para isso. É preciso forte liderança, persistência e paciência para introduzi-las e superar a resistência dos empregados.

O fluxo de informações traz a capacidade de uma empresa de assegurar direitos de decisão claros, bem como a capacidade de avaliar e motivar as pessoas, mas com uma ressalva crítica: 
a informação. Certificar-se de que há informações de alta qualidade disponíveis e fluindo por toda organização é uma das tarefas mais desafiadoras da empresa moderna e um dos fatores que contribuem para o alto desempenho e a vantagem competitiva mais afirmativa. Katzenbach (2004) afirma que frequentemente é possível observar na prática a vinculação entre informação e desempenho, ignorando que melhores fluxos de informações fazem mais do que reduzir custos, pois realocam recursos escassos com mais eficiência.

Essas práticas estão sempre entrelaçadas, entretanto, a criação desse tipo de organização não ocorre rapidamente e sempre há a necessidade de promover uma sintonia fina. Isso pode explicar porque os líderes de empresas que estão passando por problemas não têm paciência para mudar os direitos de decisão, os itens motivacionais e os fluxos de informação.

De acordo com Slack(1996), que apresenta o encadeamento entre a integração das áreas nas empresas conforme o descrito na figura 2 é mais fácil cortar a estrutura do que despender tempo para garantir que as mudanças estruturais realmente resultem em melhorias de produtividade sustentáveis e ganhos para o acionista.

Contudo, a ação de se negligenciar esse trabalho também pode explicar parcialmente por que alguns desses líderes não estão mais no comando. Organizar-se para executar estes procedimentos dá (requer) trabalho, mas se tornou de fato um determinante para a obtenção de vantagem competitiva.

Uma empresa assume uma posição de vantagem competitiva em face dos seus concorrentes quando evidencia, durante um grande período de tempo, uma ou mais das seguintes características: capacidade de manter um preço abaixo dos seus concorrentes; reputação de qualidade no atendimento ou nos produtos que produz e comercializa; preferência por parte dos clientes; lucratividade acima da média do setor em que atua.

De um modo geral, a origem da vantagem competitiva de uma empresa decorre de um conjunto de circunstâncias que se complementam e se reforçam. Via de regra, a empresa deve ser capaz de se destacar dos seus concorrentes, segundo a percepção dos clientes, que estão sempre buscando o maior valor incorporado aos produtos, ao menor custo possível. É esta a chave da vantagem competitiva: oferecer valor aos clientes e cobrar baixos preços.

Para que uma empresa consiga sustentar uma vantagem competitiva por muito tempo, é necessário que a sua administração esteja permanentemente orientada para o acompanhamento do mercado, de tal forma a aproveitar as oportunidades que ele oferece, bem como ser capaz de se defender de eventuais ameaças. É esta postura que caracteriza uma estratégia competitiva.

É fundamental que os gestores compreendam que o futuro e a continuidade das operações do negócio dependem de uma vantagem de custo ou de uma vantagem de valor, ou, o que seria a situação ideal, de ambos os aspectos. Estas duas fontes de vantagem competitiva deverão se refletir nos lucros da empresa.

Os baixos custos permitem que uma empresa possa reduzir seus preços de venda, sem comprometer as margens de lucro, ou seja, permitem que a empresa venda seus produtos e obtenha o mesmo lucro por unidade vendida.

Por sua vez, a vantagem de valor é representada pela identificação, por parte do cliente, de aspectos que diferenciam o produto da empresa daqueles oferecidos pela concorrência. Estes aspectos estão sempre associados a maiores benefícios proporcionados ao cliente, em termos 
de praticidade, satisfação, conveniência etc. Dizemos que um produto que possui maior valor incorporado tem um maior conteúdo utilitário. Hoje em dia, em razão da convergência tecnológica, há uma busca constante por maior conteúdo utilitário.

Existe uma afirmação em Marketing que diz que os clientes não compram produtos e sim os benefícios a eles associados. Os benefícios tanto podem ser funcionais, ou seja, relativos ao uso para o qual o produto se destina, quanto podem ser intangíveis, tais como a imagem ou os serviços que o acompanham.

O valor pode ser incorporado quando a estratégia do negócio esta focada na sua obtenção. Quando uma empresa passa a analisar com mais detalhes o mercado, é provável que descubra a existência de distintos segmentos de valor. Os segmentos de valor correspondem aos diferentes grupos de clientes no conjunto do mercado que atribuem importâncias distintas a múltiplos benefícios relacionados a um mesmo tipo de produto.

O exemplo mais representativo desta situação é o que ocorre no mercado de automóveis, quando encontramos um modelo básico, com um número mínimo de itens de série, e verificamos a existência de vários modelos aos quais vão sendo incorporadas outras utilidades, tais como um motor mais potente, ar condicionado, direção hidráulica, air-bag, entre outros. À medida que os veículos do mesmo gênero vão incorporando mais e mais utilidades, seu preço vai aumentando. Para os diferentes preços existem distintos segmentos de clientes dispostos a comprá-los.

Outra forma que pode ser empregada para aumentar o valor é o uso dos serviços, o que, por sua vez, impõe maiores responsabilidades ao gerenciamento logístico. Os serviços estão vinculados ao processo de relacionamento com os clientes por meio da ampliação da oferta e compreendem, por exemplo, serviços de entrega, serviços pós-venda, oportunidades de financiamentos, suporte técnico etc.

Ballou (2006, p.37) lembra que qualquer que seja o produto ou serviço transacionado, ele perde grande parte de seu valor quando não está ao alcance dos clientes no momento e lugar adequados para o seu consumo.

Figura 2 - Integração de áreas

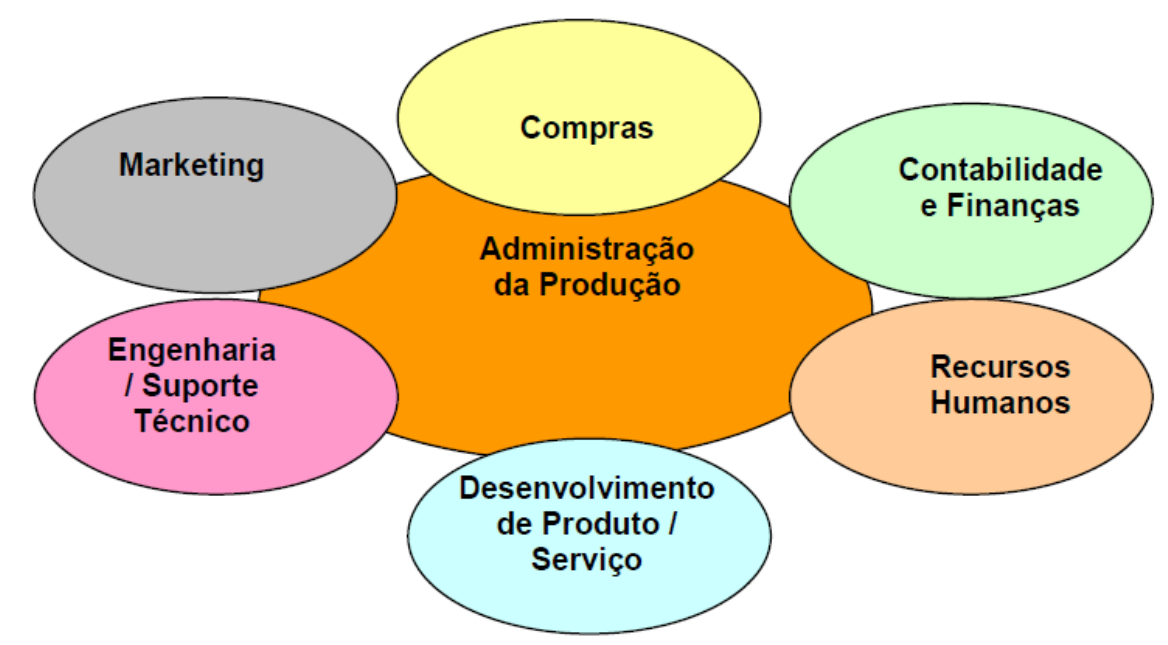

Fonte: SLACK, N. Administração da Produção, São Paulo, Atlas, 1999 


\section{CONCLUSÃo}

No presente trabalho, procuramos demonstrar a importância das contribuições que cada escola apresenta para a caracterização do comportamento empreendedor. A partir desse estudo e análise, pode-se estabelecer um processo empreendedor baseado em quatro pilares:

- reconhecimento de oportunidades

- gerenciamento

- reconhecer necessidades de mudança

- auto-avaliacão

Nesse sentido, a idéia de que cada ator na organização possui um cliente específico, e que deve posicionar-se no sentido de buscar um alinhamento entre o atendimento da demanda deste cliente e o atendimento da missão organizacional, constitui-se no grande diferencial estratégico a ser perseguido, de tal forma a promover vantagens competitivas e retornos para todos os stakeholders. Tais considerações avultam de importância no atual estágio de acirrada variabilidade dos mercados e da mudança do ambiente competitivo. No entanto, apesar das múltiplas abordagem apresentadas diferirem eventualmente em seus núcleos de pensamento, é importante que se conclua que cada linha de pensamento tem sua importância e adequação, dependendo do tipo de análise a ser feita.

\section{REFERÊNCIAS}

BALLOU, RONALD H. Gerenciamento da cadeia de Suprimentos / Logística Empresarial. 5a ed. - Porto Alegre: Bookman, 2006.

KORNIJEZUK, Fernando Bandeira Sacenco. Características Empreendedoras de Pequenos Empresários de Brasília, 2004.

LEVITT, THEODORE. Miopia em Marketing, in Harvard Business Review, setembro-outubro, 1975.

LISCHERON,Joe. Defining Entrepreneurship, Journal of Small Business Management, 1991.

NEILSON, GARY, L. Strategy a Business, Booz Allen Hamilton. Chicago, 2002.

KATZENBACH, JON, Orgulho e Estratégia. Revista HSM Management. Edição Nov-Dez 2004, p.178- 182.

PINCHOT, GIFFORD. Intrapreneuring in Action. Berrett-Koehler Publishers, Inc., 1999. p.172-173.

SLACK, NIGEL, et al. Administração da Produção, Edição Compacta. Editora Atlas, 1996. 